\title{
Comparison of tracheal intubation and alternative airway techniques performed in the prehospital setting by paramedics: a systematic review
}

\author{
Jan L. Jensen, ACP, BSc; ${ }^{* \dagger}$ KaWai Cheung, MD; ${ }^{\ddagger}$ John M. Tallon, MD, MSc; ${ }^{*}$ Andrew H.Travers, MD, MSc ${ }^{\S}$
}

\section{ABSTRACT}

This systematic review included controlled clinical trials comparing tracheal intubation ( $\mathrm{TI}$ ) with alternative airway techniques (AAT) (bag-mask ventilation and use of extraglottic devices) performed by paramedics in the prehospital setting. A priori outcomes to be assessed were survival, neurologic outcome, airway management success rates and complications. We identified trials using EMBASE, MEDLINE, CINAHL, The Cochrane Library, Web of Science, author contacts and hand searching. We included 5 trials enrolling a total of 1559 patients. No individual study showed any statistical difference in outcomes between the TI and AAT groups. Because of study heterogeneity, we did not pool the data. This is the most comprehensive review to date on paramedic trials. Owing to the heterogeneity of prehospital systems, administrators of each system must individually consider their airway management protocols.

Keywords: paramedic, prehospital, airway, tracheal intubation, extraglottic, supraglottic, bag-mask ventilation

\section{RÉSUMÉ}

Cette analyse systématique portait sur les essais cliniques contrôlés comparant l'intubation trachéale aux techniques alternatives de prise en charge des voies respiratoires (ventilation avec masque et ballon et utilisation de dispositifs extraglottiques) réalisées par le personnel paramédical en préhospitalier. Les résultats a priori à évaluer étaient la survie, les résultats neurologiques, les taux de réussite de la prise en charge des voies respiratoires et les complications. Les essais ont été recensés en interrogeant les bases de données EMBASE, MEDLINE, CINAHL, la Bibliothèque Cochrane, Web of Science, en communiquant avec les auteurs et en effectuant une recherche manuelle. Nous avons inclus 5 essais auxquels ont participé 1559 patients en tout. II n'y avait pas de différence statistique entre les résultats des groupes d'intubation trachéale et de techniques alternatives de prise en charge des voies respiratoires dans aucun des essais. En raison de I'hétérogénéité de l'étude, les données n'ont pas été mises en commun. C'est l'analyse la plus détaillée à ce jour sur les études relatives aux interventions paramédicales. En raison de I'hétérogénéité des systèmes préhospitaliers, les administrateurs de chaque système doivent examiner leur propre protocole de prise en charge des voies respiratoires.

\section{INTRODUCTION}

With widespread support, ${ }^{1,2}$ prehospital tracheal intubation (TI) by paramedics has rapidly expanded among North American emergency medical services (EMS) systems. Indeed, prehospital TI has been associated with improved outcomes in traumatic brain injury, ${ }^{3}$ neardrowning ${ }^{4}$ and pediatric resuscitation. ${ }^{5}$ However, recent studies have questioned the effectiveness of this intervention. In the Ontario Prehospital Advanced Life Support Study, outcomes were similar for trauma and cardiac arrest patients treated by advanced life-support paramedics compared with those treated by basic life support paramedics. ${ }^{6,7}$ Furthermore, 3 recent trials on prehospital patients with traumatic brain injury have demonstrated that prehospital TI was associated with increased mortality when compared with emergency department TI..$^{8-10}$ Other studies have suggested that increased mortality

From the *Division of Emergency Medical Services, Dalhousie University, tEmergency Health Services, Dartmouth, NS, the ¥Emergency Department, Vancouver General Hospital, Vancouver, BC, and §Emergency Health Services, Office of the Provincial Medical Director, Dartmouth, NS

The abstract was presented as a poster presentation at 2 conferences: National Association of EMS Physicians Scientific Assembly, Jan. 22-24, 2009, Jacksonville, Fla., and Canadian Cochrane Symposium, Mar. 11-12, 2009, Halifax, NS.

Submitted Apr. 9, 2009; Revised Sep. 8, 2009, Oct. 3, 2009, Oct. 29, 2009; Accepted Nov. 11, 2009

This article has been peer reviewed.

CJEM 2010;12(2):135-40 
may not be related to prehospital intubation per se, but rather to prehospital hypocarbia and/or hypercarbia, ${ }^{11}$ or hypoxia. ${ }^{12}$ This systematic review is a comprehensive analysis of paramedic trials comparing prehospital TI with alternative airway techniques (AAT).

\section{METHODS}

We conducted a comprehensive search of the following databases: EMBASE (1974-January 2009), MEDLINE (January 1966-January 2009), CINAHL (1982-January 2009), The Cochrane Library (Issue 4, 2008) and Web of Science (1980-January 2009). We used no language or publication restrictions.

\section{Search strategy}

The search strategy consisted of the following terms: (intubation OR intratracheal intubation [medical subheading, MeSH] OR endotracheal intubation) AND (emergency medical services [MeSH] OR emergency medical technicians $[\mathrm{MeSH}])$ OR emergenc* OR prehospital OR paramedic* OR emergency care. We assessed reference lists of literature reviews, position statements and included studies, and contacted authors of included studies for additional studies.

\section{Study selection}

We pulled full-text articles whose titles or abstracts indicated they were systematic reviews, consensus statements, randomized controlled trials, quasi-randomized controlled trials or cohort studies that involved advanced airway management by paramedics in the prehospital setting, comparing TI with AAT. We limited AAT interventions to bag-mask ventilation or extraglottic devices (EGDs). We defined "paramedic" as any clinician (including all levels of emergency medical technicians) who provides prehospital care, excluding physicians, nurses and respiratory therapists. Included studies had to report one of the following outcomes: survival, neurologic outcomes, airway management success rates or complications. We assessed the following complications: rates of hypoxemia $\left(\mathrm{SaO}_{2}, \mathrm{PO}_{2}\right)$, hypercarbia $\left(\mathrm{PCO}_{2}\right)$, hypotension and aspiration. Final inclusion was limited to randomized controlled trials and quasirandomized controlled trials. Two investigators (J.L.J., K.C.) independently selected citations for full-text review and final inclusion. Disagreement was resolved by third party adjudication.

\section{Validity assessment}

Two reviewers independently assessed the methodological quality of each included study using the criteria by Jadad and colleagues ${ }^{13}$ and the risk of bias assessment with Review Manager 5.0 software (Cochrane Collaboration). ${ }^{14}$ The Jadad scale (0-5) determines quality of clinical trials based on study randomization, presence of double-blinding, description of withdrawals and process of randomization and blinding. ${ }^{13}$

\section{Data abstraction and analysis}

The following data were abstracted from each included study: location of study, details of the prehospital system, paramedic training, population studied, intervention, comparison and our predefined outcomes. Two reviewers independently extracted data from all included studies and double entered the data into the Review Manager 5.0 software.

For dichotomous outcomes, we calculated statistics as odds ratios with $95 \%$ confidence intervals (CIs). For continuous outcomes, we calculated statistics as standardized mean differences with 95\% CIs. We assessed heterogeneity using the $I^{2}$ statistic $^{15}$ and the BreslowDay $\chi^{2}$ test $^{16}$ with significance denoted by $p<0.10$. We visually examined the presence of publication bias using a funnel plot. ${ }^{17}$

\section{RESULTS}

\section{Selection of studies}

The search resulted in 4408 citations, of which 257 fulltext articles (or abstracts when full-text articles were unavailable) were retrieved for review. Five randomized controlled trials or quasi-randomized controlled trials met inclusion criteria (Fig. 1).

\section{Description of included studies}

Five studies involving a total of 1559 patients were included. Included studies are summarized in Table 1. The majority of patients in each study ${ }^{18-22}$ were in cardiac and/or respiratory arrest. Four trials ${ }^{19-22}$ included only adult patients and one trial ${ }^{18}$ included only pediatric patients. Four trials compared TI to an EGD, ${ }^{19-22}$ and one study ${ }^{18}$ compared TI to bag-mask ventilation. Extraglottic devices used in the 4 studies were the Combitube, ${ }^{21,22}$ the pharyngeotracheal lumen airway ${ }^{19}$ 
and the esophageal gastric tube airway. ${ }^{20}$ All studies provided additional airway training to paramedics for the purposes of the study. Only one trial ${ }^{21}$ was conducted in a rural setting.

\section{Methodological quality assessment}

We used the Jadad scale (included in Table 1) and risk of bias assessment (Table 2) to determine the methodological quality of all included studies. All included studies had methodological limitations. Only the trial by Goldenberg and colleagues ${ }^{20}$ was a true randomized controlled trial design. However, incorrect randomization occurred in $17 \%$ of patients, and age was significantly higher in the AAT group. ${ }^{20}$ In the study by Gausche and coauthors, ${ }^{18}$ only $42 \%$ of patients in the TI group actually received TI. The study by Staudinger and colleagues ${ }^{21}$ used an as-treated analysis and did not describe baseline characteristics.

\section{Effect of interventions}

Owing to study heterogeneity as a result of dissimilar prehospital systems, we did not pool data on variation in paramedic training, enrolled patients and airway devices used.

Individually, however, each study had similar results. Airway management success rates, as determined by the paramedic, were measured in 4 trials..$^{18,20-22}$ The study by Rumball and colleagues ${ }^{22}$ also measured success as determined by the receiving emergency physician.

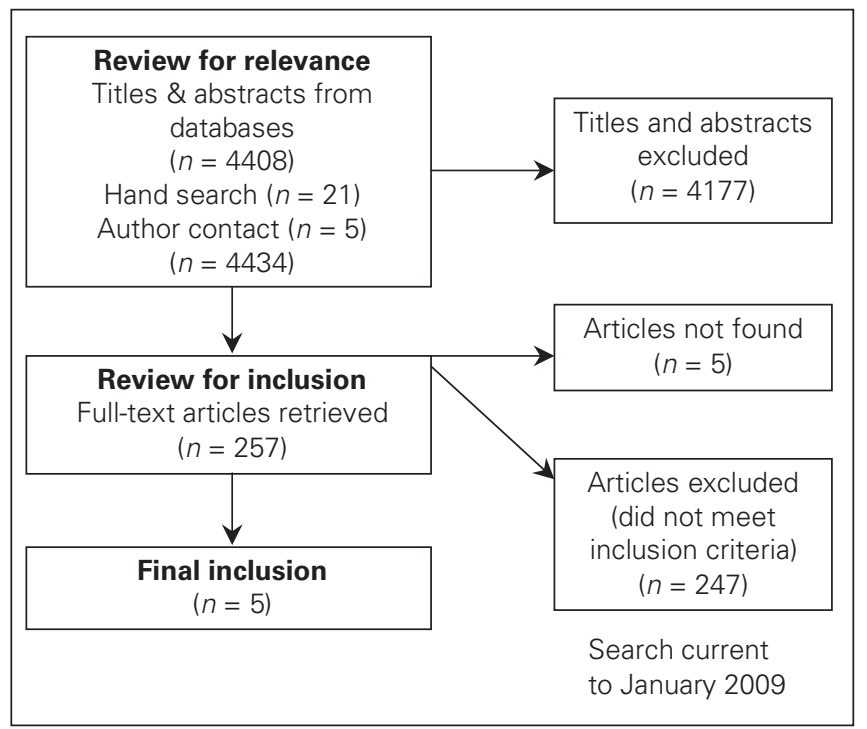

Fig. 1. Flow chart for titles and abstracts included in the review.
Individually, no study showed any difference in success rates between the TI and AAT groups.

Hypoxemia $\left(\mathrm{PaO}_{2}, \mathrm{SaO}_{2}\right)$ and/or hypercarbia $\left(\mathrm{PaCO}_{2}\right)$ were measured in 3 studies. ${ }^{18-20}$ The trials by Bartlett and colleagues ${ }^{19}$ and Goldenberg and coauthors ${ }^{20}$ measured arterial blood gas, and the trial by Gausche and coauthors ${ }^{18}$ measured oxygen saturation on arrival to the emergency department. No individual study demonstrated any mean difference in arterial blood gas results.

Aspiration rates, measured in 2 studies, ${ }^{18,20}$ were also similar between the TI and AAT groups. The study by Gausche and colleagues ${ }^{18}$ measured aspiration rates and the trial by Goldenberg and coauthors ${ }^{20}$ measured aspiration pneumonia rates in patients admitted to hospital.

Good neurologic outcome at discharge was similarly defined in the studies that included this outcome. In the study by Gausche and coworkers, ${ }^{18}$ good neurologic outcome was defined as normal, no change from baseline or mild deficit, using a modified Pediatric Cerebral Performance Category Scale. In the studies by Goldenberg and coworkers ${ }^{20}$ and Staudinger and colleagues, ${ }^{21}$ good neurologic outcome was defined as no neurologic residual. No study demonstrated a significant difference in rates of good neurologic outcome at discharge between the TI and AAT groups. ${ }^{18,20,21}$

Finally, survival to hospital admission, measured in the studies by Goldenberg and colleagues ${ }^{20}$ and Staudinger and coauthors, ${ }^{21}$ and survival to discharge, measured in the studies by Gausche and colleagues, ${ }^{18}$ Goldenberg and coworkers, ${ }^{20}$ and Staudinger and coauthors, ${ }^{21}$ did not differ between the TI and AAT groups in any of the studies. Individually, no included study demonstrated any difference between the TI and AAT group in any of our a priori outcomes.

\section{Subgroup analysis}

As studies were not pooled, insufficient data was available for subgroup analyses.

\section{DISCUSSION}

This is the most comprehensive review to date on paramedic prehospital TI versus AAT. Using our inclusion criteria, we included 2 more studies than a recently published Cochrane systematic review comparing TI with other airway management techniques. ${ }^{23}$ We found no significant differences in our a priori outcomes comparing TI with AAT. However, it is noteworthy that outcomes 


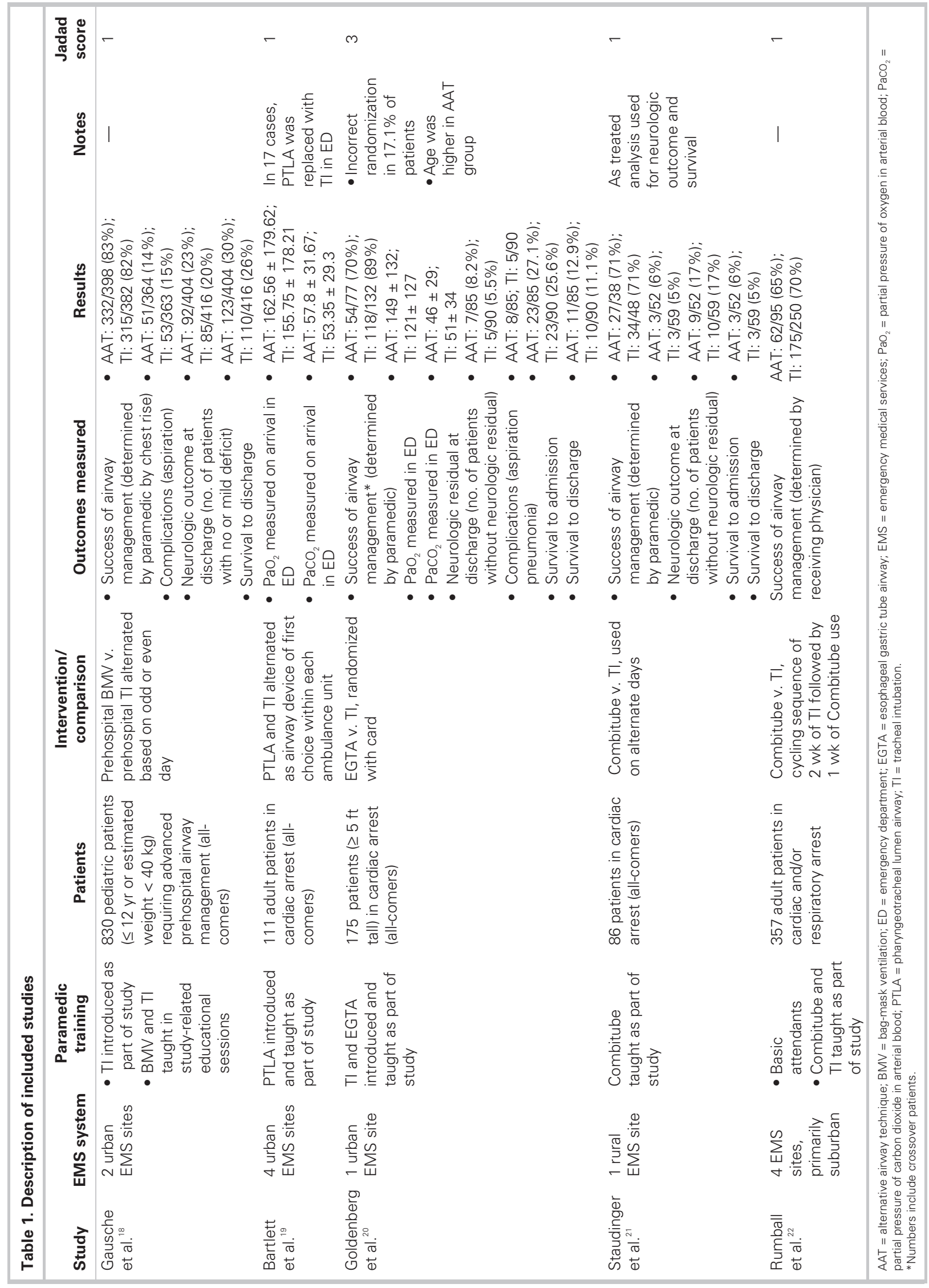


Table 2. Risk of bias assessment (methodological quality summary). Review of authors' judgments about each methodological quality item for each included study

$\begin{array}{lcccccc}\text { Study } & \begin{array}{c}\text { Adequate sequence } \\ \text { generation }\end{array} & \begin{array}{c}\text { Allocation of } \\ \text { concealment }\end{array} & \text { Blinding } & \begin{array}{c}\text { Incomplete outcome } \\ \text { data addressed }\end{array} & \begin{array}{c}\text { Free of selective } \\ \text { reporting }\end{array} & \begin{array}{c}\text { Free of other } \\ \text { bias }\end{array} \\ \text { Gausche et al. }^{18} & \text { No } & \text { No } & ? & \text { Yes } & \text { Yes } & \text { Yes } \\ \text { Bartlett et al. }^{22} & \text { No } & \text { No } & ? & \text { Yes } & \text { Yes } & \text { ? } \\ {\text { Goldenberg et al. }{ }^{20}}^{21} & \text { Yes } & ? & ? & \text { Yes } & \text { Yes } \\ \text { Staudinger et al. } & \text { No } & \text { No } & ? & \text { Yes } & \text { Yes } \\ \text { Rumball et al. }{ }^{22} & \text { No } & \text { No } & ? & \text { No } & \text { Yes }\end{array}$

may not be associated with the actual performance of TI, but may be related to the specific prehospital system and factors such as mastery of the skill, ${ }^{24}$ paramedic practice ${ }^{25}$ and cognitive decision-making during the procedure. ${ }^{26}$ Further study is indicated to determine whether specific subgroups may benefit from either prehospital TI or AAT. The administrators of individual EMS systems must assess factors including patient volume and paramedic training to determine optimal management of prehospital patients requiring advanced airway management.

\section{Limitations}

Our review has several important limitations. There are very few randomized or quasi-randomized controlled trials on this topic, and included studies scored low on the Jadad scale. ${ }^{13}$ Two of the studies ${ }^{19,20}$ included EGDs that are currently not in use: the pharyngeotracheal lumen airway and the esophageal gastric tube airway. The included studies often did not fully describe EMS systems. Tracheal intubation was introduced in 3 of the studies $^{18,20,22}$ and the use of the EGD was taught as part of 4 studies. ${ }^{19-22}$ The skill of TI is generally considered to be more difficult than the skill of EGD insertion, ${ }^{24}$ and similar outcomes between the TI and AAT groups may indicate that TI in the hands of skilled paramedics may be superior to the use of EGDs. Consequently, results may not be reflective of prehospital systems where TI and AAT have been more established. Trauma patients made up a small minority of the total included patients, and we did not find any studies involving air medical transport or rapid sequence intubation that met inclusion criteria. Although there was no statistically significant heterogeneity between the studies, important differences existed so we did not pool data.

\section{CONCLUSION}

We have conducted a systematic review comparing TI with the use of alternative airway devices in the prehos- pital setting by paramedics. Existing data are limited. This review demonstrates that current evidence does not support a difference in outcome between TI and AAT.

Acknowledgements: We thank Mr. Tim Ruggles, BA, MLS, Dalhousie University Kellogg Health Sciences Library, for his assistance with developing the search strategies for the database searches. We also acknowledge Mr. Max Ratmirov, Primary Care Paramedic, Emergency Health Services, for his assistance in translation of an article.

\section{Competing interests: None declared.}

\section{REFERENCES}

1. Emergency Cardiac Care Committee and Subcommittees, American Heart Association. Guidelines for cardiopulmonary resuscitation and emergency cardiac care. Part VI. Pediatric advanced life support. JAMA 1992;268:2262-75.

2. Dunham CM, Barraco RD, Clark DE, et al. Guidelines for emergency tracheal intubation immediately after traumatic injury. 7 Trauma 2003;55:162-79.

3. Winchell RJ, Hoyt DB. Endotracheal intubation in the field improves survival in patients with severe head injury. Arch Surg. 1997;132:592-7.

4. Losek JD, Hennes H, Glaeser P, et al. Prehospital care of the pulseless, non-breathing pediatric patient. Am 7 Emerg Med $1987 ; 5: 370-4$

5. Sirbaugh PE, Pepe PE, Shook JE, et al. A prospective, population-based study of the demographics, epidemiology, management, and outcome of out-of-hospital pediatric cardiopulmonary arrest. Ann Emerg Med 1999;33:174-84.

6. Stiell IG, Wells GA, Field B, et al. Advanced cardiac life support in out-of-hospital cardiac arrest. NEngl J Med 2004;351:647-56.

7. Stiell IG, Nesbitt LP, Pickett W, et al. The OPALS major trauma study: impact of advanced life-support on survival and morbidity. CMA72008;178:1141-52.

8. Murray JA, Demetriades D, Berne TB, et al. Prehospital intubation in patients with severe head injury. 7 Trauma 2000; 49:1065-70.

9. Davis DP, Hoyt DB, Ochs M, et al. The effect of paramedic rapid sequence intubation on outcome in patients with severe traumatic brain injury. 7 Trauma 2003;54:444-53.

10. Bochicchio GV, Ilahi O, Joshi M, et al. Endotracheal intubation in the field does not improve outcome in trauma 
patients who present without an acutely lethal brain injury. J Trauma 2003;54:307-11.

11. Warner KJ, Cuschieri J, Copass MK, et al. The impact of prehospital ventilation on outcome after severe traumatic brain injury. 7 Trauma. 2007;62:1330-6.

12. Chi JH, Knudson MM, Vassar MJ, et al. Prehospital hypoxia affects outcome in patients with traumatic brain injury: a prospective multicenter study. J Trauma 2006;61:1134-41.

13. Jadad AR, Moore RA, Carroll D, et al. Assessing the quality of reports of randomized control trials: Is blinding necessary? Control Clin Trials 1996;17:1-12.

14. Higgins JPT, Green S, editors. Cochrane Handbook for Systematic Reviews of Interventions Version 5.0.2 [updated September 2009]. The Cochrane Collaboration; 2009. Available: www.cochrane-handbook.org (accessed 2010 Jan 21).

15. Higgins JP, Thompson SG, Deek JJ. Measuring inconsistency in meta-analyses. BMJ 2003;327:557-60.

16. Breslow NE, Day NE. Statistical methods in cancer research. Volume I - the analysis of case-control studies. IARC Sci Publ 1980:5-338.

17. Egger M, Davey Smith G, Schneider M, et al. Bias in metaanalysis detected by a simple, graphical test. BMJ 1997;315: 629-34.

18. Gausche M, Lewis RJ, Stratton SJ, et al. Effect of out-ofhospital pediatric endotracheal intubation on survival and neurological outcome. JAMA 2000;283:783-90.

19. Bartlett RL, Martin SD, McMahon JM, et al. A field comparison of the pharyngeotracheal lumen airway and the endotracheal tube. 7 Trauma 1992;32:280-4.

20. Goldenberg IF, Campion BC, Siebold CM, et al. Morbidity and mortality in patients receiving the esophageal obturator airway and the endotracheal tube in prehospital cardiopulmonary arrest. Minn Med 1986;69:707-13.

21. Staudinger T, Brugger S, Roggla $M$, et al. Comparison of the combitube with the endotracheal tube in cardiopulmonary resuscitation in the prehospital phase. Wien Klin Wochenschr 1994;106:412-5.

22. Rumball C, MacDonald D, Barber P, et al. Endotracheal intubation and esophageal tracheal combitube insertion by regular ambulance attendants: a comparative trial. Prebosp Emerg Care 2004;8:15-22.

23. Lecky F, Bryden D, Little R, et al. Emergency intubation for acutely ill and injured patients. Cochrane Database Syst Rev 2008;2:CD001429.

24. Mulcaster JT, Mills J, Hung OR, et al. Laryngoscopic intubation: learning and performance. Anaesthesiology 2003;98:23-7.

25. Kovacs G, Bullock G, Ackroyd-Stolarz S, et al. A randomized controlled trial on the effect of educational interventions in promoting airway management skill maintenance. Ann Emerg Med 2000;36:301-9.

26. Wang HE, Katz SH. Cognitive control and prehospital endotracheal intubation. Prehosp Emerg Care 2007;11:234-9.

Correspondence to: Jan Jensen, Emergency Medical Services, QEII Health Sciences Centre, 1796 Summer St., Rm. 3022, Halifax NS B3H 3A7; jljensen@dal.ca

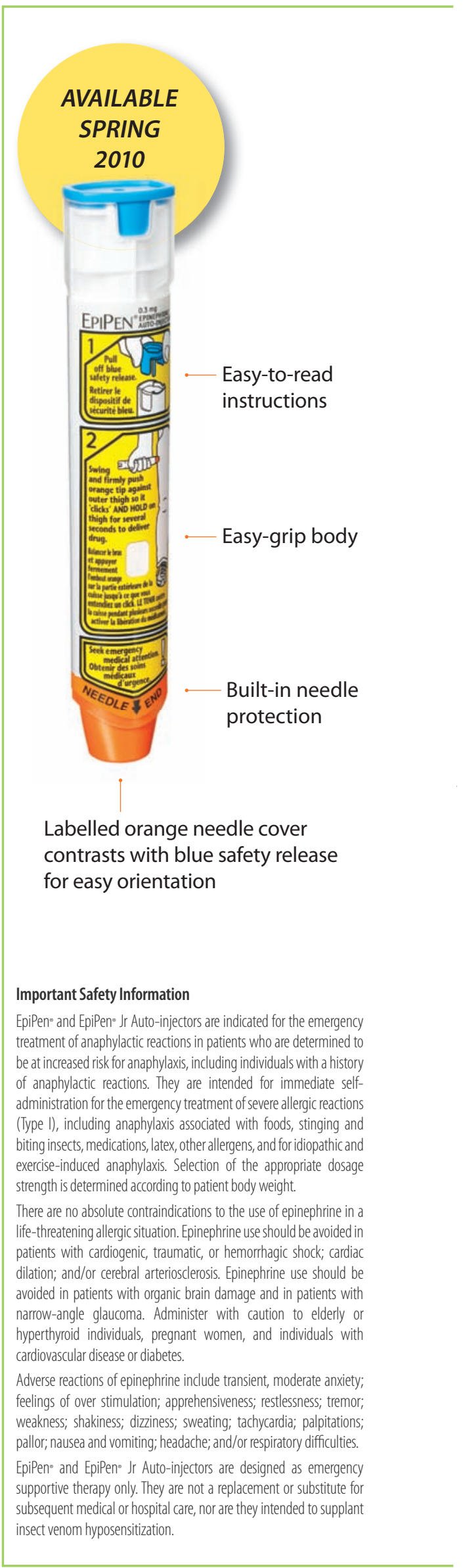

